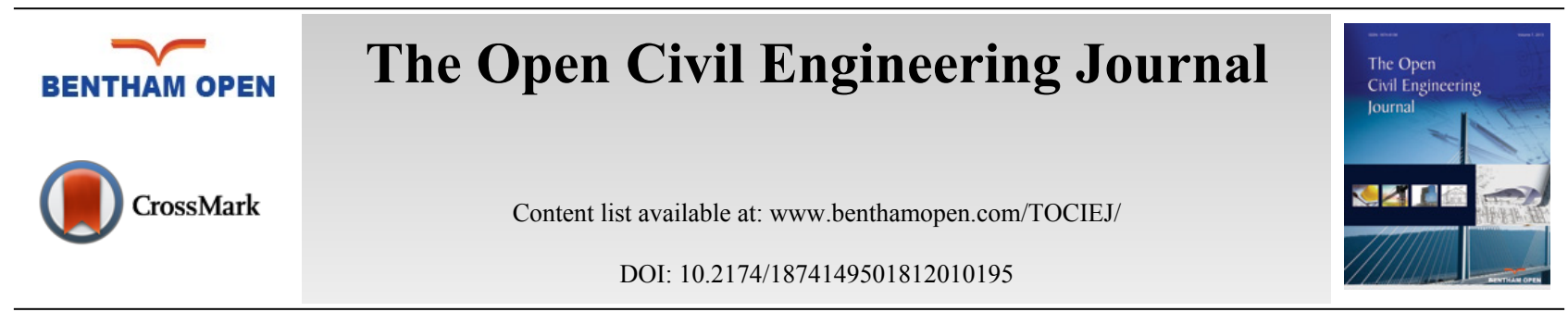

REVIEW ARTICLE

\title{
Review of Guidelines for Seismic Design of Structures with Damping Systems
}

\author{
Sonia E. Ruiz* \\ Instituto de Ingeniería, Universidad Nacional Autónoma de México, Coyoacán, 04510, Ciudad de Mexico, Mexico
}

Received: April 25, 2018

Revised: June 1, 2018

Accepted: June 8, 2018

\begin{abstract}
:
Objective:

The purpose of this paper is to present an overview of the specifications of three guidelines for the seismic design of structures with passive dampers, to compare their similarities, as well as to discuss topics in which each guideline would be desirable to extend. The guidelines compared here are: a) Minimum Design Load for Buildings and Other Structures (ASCE/SEI 7-16), b) European Standard Anti-seismic Devices (EN 15129), and c) Technical Regulations for Seismic Design, corresponding to Mexico City Building Code (NTCS-17).
\end{abstract}

\section{Methods:}

The document summarizes and discusses the most significant differences and similarities among the three guidelines for the design of structures with energy dissipation devices. The analysis and discussion are focused on the following sections: 1) Type of Dissipation Devices, 2) General Design Requirements, 3) Procedure Selection, 4) Seismic Design Action, 5) Inspection and 6) Testing of Dissipaters.

\section{Conclusion:}

The paper identifies the gaps in each guideline and gives recommendations about its possible extension. The paper concludes that ASCE/SEI 7-16 presents the procedure selection section with more detail; EN 15129 describes with more detail the Testing section, and NTCS-17, the Inspection section. The paper can be useful for engineers and guideline writers from the USA, Europe, Mexico and other countries that are in process of developing their guidelines for structures with supplementary damping.

Keywords: Buildings with dampers, Energy dissipating devices, American, Mexican and European design recommendations, Anti Seismic Devices, Testing of Dissipater, Seismic Design Action.

\section{INTRODUCTION}

Different guidelines for the design of structures with anti-seismic devices have been published since several decades ago [1 - 9]; the first of them were oriented to the seismic isolation of structural systems, then, the recommendations were extended to structures with passive energy dissipation devices [10 - 17].

Here, the following guidelines for designing structures with damping devices are reviewed and compared: a) Minimum Design Load for Buildings and other Structures ASCE/SEI 7-16 (ASCE 7-16) [9], b) European Standard Anti-seismic Devices EN 15129 [4], and c) Technical Regulations for Seismic Design (Normas Técnicas Complementrias para Diseño por Sismo (NTCS-17) [18], which is part of the Mexico City Building Code. These documents correspond to the USA, Europe and Mexico, respectively. The analysis was done in accordance with the following sections order: 1) Type of devices, 2) General design requirements, 3) Procedure selection, 4) Seismic design

* Address correspondence to this author at the Institute of Engineering, Dept. of Structural Engineering, Universidad Nacional Autónoma de México, Coyoacan, 04510 Ciudad de Mexico, Mexico. Tel: 52 (55) 56233654, E-mail: sruizg@iingen.unam.mx 
action, 5) Inspection, and 6) Testing. Requirements specified in each section of each document were compared and discussed in what follows.

\section{TYPE OF DISSIPATION DEVICES}

Passive seismic energy devices are commonly classified as follows: 1) those where the dissipated energy depends on the relative displacement between each end of the systems (called Displacement Dependent Devices, DDD, or hysteretic devices), and 2) those where it depends on its relative velocity (called Velocity Dependent Devices, VDD). This classification is used in Chapter 18 of ASCE 7-16 [9], in Appendix B of NTCS-17 [18], and in the European guidelines EN 15129 [4].

\section{GENERAL DESIGN REQUIREMENTS}

The recommendations given by the guidelines for the design of structures with energy dissipating devices require to satisfy their own philosophy [19] as well as their general requirements for the design of conventional structures (without dissipating devices). For example, the structure-energy dissipating system shall be designed taking into account the type of structure, structural configuration, classification, type of seismic zone where the structure is located; as well as to satisfy the specifications related to different structural effects, such as torsion, P-Delta effects, etc.

\subsection{Structure - Damping System}

With respect to the structure-damping system design, the three documents present similar recommendations; however, they also present some specifications that are different. Similitudes and differences among the documents with respect to the structure-damping system design, as well as some gaps in the guidelines, are mentioned as follows:

a. ASCE 7-16 and NTCS-17 assume that the structure-energy dissipation system is constituted by a primary system (force-resisting system) plus a secondary system (formed by the dampers and the elements that transfer forces from them to the primary system, or alternatively, to the base of the structure), although both systems may have common elements.

b. EN 15129 and NTCS-17 recommend that the actions transmitted by the dissipation device to the connections shall be multiplied by a factor equal to 1.1 and 1.2, respectively. Similarly, ASCE 7-16 specifies that forcecontrolled elements of the secondary system shall be designed for seismic forces that are increased by $20 \%$ from those corresponding to the average maximum credible earthquake response. It is noticed that the increase in the force is applied to the actions on the force-controlled elements, rather than to each structural element.

c. Sections 18.2.4.4 and 18.2.4.5 of ASCE 7-16 mention maximum and minimum property modification $(\lambda)$ factors to be used in the analysis and design of each damping device. The factors take into account the possible variation in damper properties above or below the nominal values. EN 15129 also considers that two sets of design properties of the devices shall be properly established; 1) upper and 2) lower bound design properties. These are representative values of a given property which are obtained from testing procedures. On the other hand, NTCS-17 does not recommend any modification factor that considers the variation with respect to nominal properties.

d. ASCE 7-16 establishes (with some exceptions) that the seismic base shear used for designing the force-resisting system shall not be less than a given limit $\left(\mathrm{V}_{\min }\right)$. This should be the greater of $\mathrm{V}_{\min }=\mathrm{V} / \mathrm{B}_{\mathrm{V}+1}$ and $\mathrm{V}_{\min }=0.75 \mathrm{~V}$, where $\mathrm{V}$ represents the unreduced seismic base shear, and $\mathrm{B}_{\mathrm{V}+1}$ is the effective damping factor (which is explained in the "Damping factor" section of the present paper). The restriction implies that the supplemental damping should not be greater than a certain value. On the other hand, no restriction on a minimum seismic base shear value has been established in NTCS-17 nor EN 15129.

\subsection{Damping System Redundancy}

Section 18.2.4.6 of ASCE 7-16 establishes that "if fewer than four energy-dissipation devices are provided in any story of a building in either principal direction, or fewer than two devices are located on each side of the center of stiffness of any story in either principal direction, all energy-dissipation devices shall be capable of sustaining displacements equal to $130 \%$ of the maximum calculated displacement in the device under $\mathrm{MCE}_{\mathrm{R}}$ ", where $\mathrm{MCE}_{\mathrm{R}}$ is defined as the "risk-targeted maximum considered earthquake ground motion response acceleration". The Design Earthquake is given by two-thirds of the corresponding $\mathrm{MCE}_{\mathrm{R}}$ ground motion. On the other hand, documents NTCS-17 
and EN 15129 do not establish any restriction with respect to the minimum number of devices that shall be installed in the building stories.

\section{PROCEDURE SELECTION}

The three guidelines (ASCE 7-16, NTCS-17 and EN 15129) recommend strength-based structural design approaches, and not a displacement-based method [20 - 23]. The methods of analysis recommended by each of the guidelines under review are the following:

a. ASCE 7-16 recommends using linear or non-linear structural analysis procedures, or a combination of these, as permitted in Section 18.2.3. The document says that regardless of the method used, the peak response of the structure and the energy dissipating system shall be confirmed with results of a time history analysis if the structure is located at a site with $\mathrm{S}_{1} \geq 0.6$, where $\mathrm{S}_{1}$ is defined as "mapped $M \mathrm{ME}_{\mathrm{R}}$, 5 percent damped, spectral response acceleration parameter at a period of $1 \mathrm{~s}$ " (see Section 11.4 of ASCE 7-16). The document explains in detail and establishes requirements for using the following approaches: $i$ ) response-spectrum procedure, $i$ ) equivalent lateral force, and iii) non-linear time history method.

b. EN 15129 establishes that the procedure selection (response spectrum or the time history analysis) depends on the type of the device used in the structure; however, the document does not specify the requirements for using each type of procedure. It is recommended that this section could be extended to a future version of the document. On the other hand, EN15129 strongly recommends that a time-history analysis shall be performed when the equivalent damping ratio related to the hysteretic energy dissipation, is higher than $15 \%$.

c. On the other hand, the document NTCS-17 does not contain specific recommendations for the analysis of buildings with energy dissipation devices. It is advisable that this section could be extended in future versions of this guideline.

It is noticed that only ASCE 7-16 specifies in detail the requirements and the methodology to be followed in the methods of analysis; and that the other two guidelines do not present such detailing.

\section{SEISMIC DESIGN ACTIONS}

The three documents reviewed here define the seismic design actions by means of design spectra or by related accelerograms. Their characteristics depend on the seismic hazard associated with the zone of interest, and their format depends on each code. In what follows, two particular issues that are of interest in the present review are analyzed with some details: Site-specific spectra, and damping coefficients which are applied to the design spectra.

\subsection{Site-Specific Spectra}

The specifications of each document with respect to the seismic design actions and the development of site-specific design spectra are mentioned as follows:

a. Section 18.2.2 of ASCE 7-16 specifies that the Design Earthquake and the Maximum Credible Earthquake $\left(\mathrm{MCE}_{\mathrm{R}}\right)$ shall be used for the design and analysis of structures with a supplementary damping. The spectra for both cases should be developed in accordance with its Section 11.4. The document (ASCE 7-16) indicates that site-specific design spectra shall be used if either of the following conditions apply: $i$ ) the structure is located on a Class F site (see Sections 11.4 .8 and 20.3.1), or $i$ ) it is located at a site where $\mathrm{S}_{1} \geq 0.6\left(\mathrm{~S}_{1}\right.$ was defined above).

b. EN 15129 refers to the seismic design action in Clause 3 of EN 1998-1 (Eurocode 8) [25], which refers to the elastic response spectrum and/or related accelerograms. El document mentions that for sites with ground conditions matching either one of the two special types $\mathrm{S}_{1}$ or $\mathrm{S}_{2}$, special studies for the definition of seismic action are required. $S_{1}$ ground types are deposits consisting or containing a layer at least $10 \mathrm{~m}$ thick of soft clays/silts with a high plasticity index $(\mathrm{PI}>40)$ and high water content; such soils have typically low values of shear-wave velocity, low internal damping, an abnormally extended range of linear behavior. Whereas, S2 ground types are deposits of liquefiable soils.

c. NTCS-17 defines the seismic design action in its Chapter 3 and in Section 6.2.1. The design acceleration spectra are determined from a software (named SASID) which can be found at the internet (www.SASID.df.gob.mx). On the other hand, NTCS-17 specifies that site-specific spectra can be developed when the geotechnical studies show the existence of anomalies in the characteristics of the soil with respect to those of its surrounding area. 
Appendix A of NTCS-17 mentions general criteria for developing site-specific spectra.

\subsection{Damping Coefficient}

The three guidelines permit that the design spectra may be reduced by a damping coefficient (or damping factor) due to the presence of dissipation devices. The damping coefficients specified by each of the documents are as follows:

a. ASCE 7-16 specifies the damping coefficient (called B) as the function of only the vibration period of the structure $(T)$, without including that of the soil. The guidelines recommend that where the structural period is greater or equal to $T_{0}$, the $B$ value is obtained from Table 1 ; however, where $T<T_{0}$, the $B$ value shall be linearly interpolated between a unity value at 0 -second period and the value at period $T_{0}$, as indicated in Table 1 , for all values of the effective damping. Here $T_{0}$ is the period at the end of the first branch of the design spectra.

Table 1. Damping Coefficient $B$.

\begin{tabular}{|c|c|}
\hline Effective Damping (Percentage of Critical) & B (where Structural Period $\geq$ T) \\
\hline$\leq 2$ & 0.8 \\
\hline 5 & 1.0 \\
\hline 10 & 1.2 \\
\hline 20 & 1.5 \\
\hline 30 & 1.8 \\
\hline 40 & 2.1 \\
\hline 50 & 2.4 \\
\hline 60 & 2.7 \\
\hline 70 & 3.0 \\
\hline 80 & 3.3 \\
\hline 90 & 3.6 \\
\hline 100 & 4.0 \\
\hline
\end{tabular}

b. The European Guidelines EN 1998-1 [24], in Section 3.2.2.2 (2), specify a general rule to calculate the B damping factor. It depends on the ratio of critical effective damping expressed as a percentage $(\zeta)$, and it is limited to 0.55 value. Equation 3.6 of EN 1998-1 [25] is as follows:

$$
B=\sqrt{\frac{0.05+\zeta}{0.10}}
$$

c. NTCS-17 specifies the damping factor shown in equation 2 (which corresponds to equation 3.1.4 of NTCS-17). It depends on the ratio of critical effective damping $(\zeta)$ and on the fundamental vibration period of the structure (T). The equation is a result of a seismic hazard based study in reference [26]. Equation 2 is divided into three parts: the first is applicable to structures with short structural vibration period $\left(T \leq T_{a}\right)$, the second to those with intermediate period $\left(T_{a}<T \leq T_{b}\right)$, and the last one to those with large structural vibration period $(T \geq)$, where $T_{a}$ and $T_{b}$ correspond to the period at the end of the first and second branch of the acceleration design spectra, respectively; and depend on the dominant vibration period of the soil $\left(T_{s}\right)$, as shown in Table 2 .

Table 2. Parameters in Ec. 3.1.4 of NTCS-17.

\begin{tabular}{|c|c|c|c|}
\hline Dominant Period of the Soil (s) & $\lambda$ & $\boldsymbol{\tau}$ & $\boldsymbol{\tau}$ \\
\hline$T_{s} \leq 0.5$ & 0.40 & 0.80 & 2.5 \\
\hline $0.5<T_{s} \leq 1.0$ & 0.45 & 0.20 & 1.0 \\
\hline $1.0<T_{s} \leq 1.5$ & 0.45 & 0.30 & 1.0 \\
\hline $1.5<T_{s} \leq 2.0$ & 0.50 & 1.20 & 1.0 \\
\hline $2.0<T_{s} \leq 2.5$ & 0.50 & 1.80 & 1.0 \\
\hline $2.5<T_{s} \leq 3.0$ & 0.55 & 3.00 & 1.0 \\
\hline $3.0<T_{s} \leq 4.0$ & 0.50 & 4.00 & 1.0 \\
\hline
\end{tabular}




$$
\beta=\left\{\begin{array}{rrr}
1-\left(1-\left(\frac{0.05}{\zeta}\right)^{\lambda}\right) \frac{T}{T_{a}} & \text { if } T \leq T_{a} \\
\left(\frac{0.05}{\zeta}\right)^{\lambda} & \text { if } T_{a}<T<\tau T_{b} \\
1+\left[\left(\frac{0.05}{\zeta}\right)^{\lambda}-1\right]\left(\frac{\tau T_{b}}{T}\right)^{\varepsilon} & \text { if } T \geq \tau T_{b}
\end{array}\right.
$$

Fig. (1) shows a comparison of the damping coefficients specified by the documents ASCE 7-16, EN 1998-1 and NTCS-17 (corresponding to Table 1, and Eq. 1 and 2), for $\zeta=30 \%$. Fig. (1) corresponds to systems located on the firm ground, and it shows that the damping coefficients recommended by ASCE-16 are more conservative than those in NTCS-17 for small and moderate vibration periods of the structure, but not for large periods. The figure also shows that the damping coefficients recommended by ASCE 7-16 are slightly more conservative than those specified by the European guidelines.

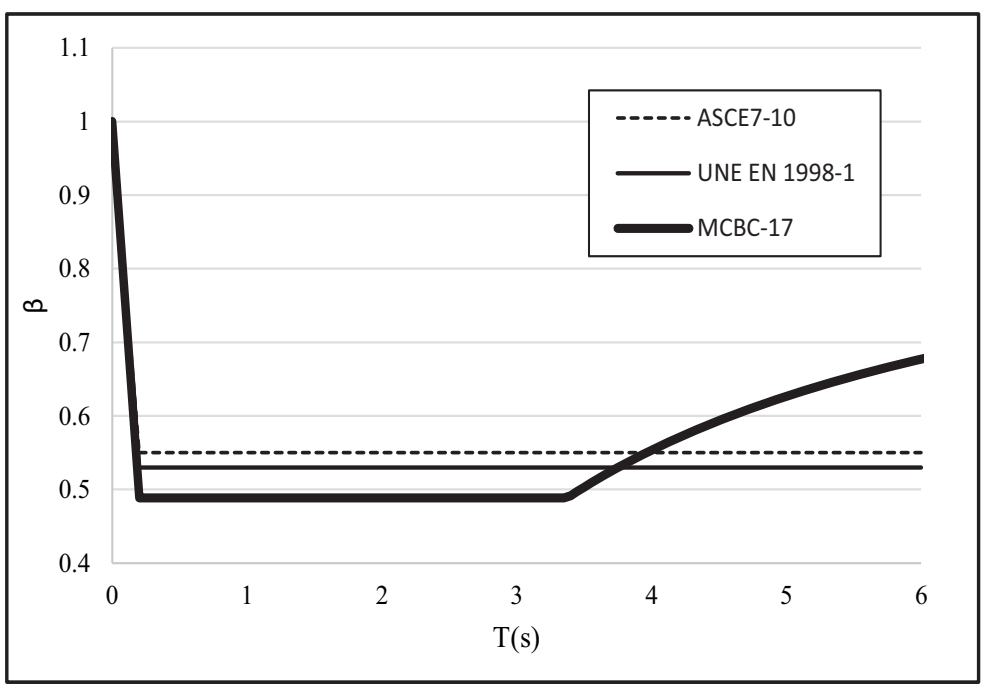

Fig. (1). Comparison of the damping coefficients.

\section{INSPECTION}

The three design guidelines specify that the structures with energy dissipating systems shall be inspected at certain intervals. The specifications of each document are as follows:

a. ASCE 7-16 recommends that: "the registered design professional responsible for the design of the structure shall establish an appropriate inspection and testing schedule for each type of damping device to ensure that the devices respond in a dependable manner throughout their design life".

b. EN 15129 specifies that a periodic inspection and maintenance program for the devices and their connections shall be elaborated during the project implementation. The guidelines indicate that the documentation shall contain a detailed description of inspection and maintenance procedures.

c. NTCS-17 specifies that the structures with supplementary damping within Group A (those whose structural failure can give place to serious consequences) and to Group B (common structures, for example, residential use, office buildings, hotels, etc) must be inspected after each intense earthquake. The document also specifies that the inspection interval for structures of Group A should not exceed 3 years, and those of Group B, it should not exceed 5 years, between two consecutive inspections. These intervals are in agreement with the occurrence of severe earthquakes $(M \geq 7.1)$ in Mexico.

It is noticed that NTCS-17 is the only document of the three under review that recommends specific intervals for inspection of the structures, while the other two design guidelines do not.

\section{TESTING}

The three guidelines specify that the energy dissipating devices used in structures shall be tested under cyclic 
loading. Some general recommendations are as follows:

a. The three guidelines permit to use representative sizes (prototypes smaller than the actual device sizes) of each type of device, provided it is accepted by the professional responsible for the design of the structure (in the case of ASCE 7-16), or by the group of professionals responsible for the tests supervision (in accordance with NTCS-17). EN 15129 requires that tests of smaller specimens shall be carried out only on specimens whose geometrical scale ratio is not less than 0.5 .

b. ASCE 7-16 and NTCS-17 recommend that the test shall be performed on two full-size damping devices corresponding to each type and each size of the device used in the design. On the other hand, EN 15129 establishes that at least one full-scale specimen shall be tested.

c. EN 15129 specifies with detail different requirements for testing: $i$ ) Displacement Dependent Devices (DDD) and $i$ ) Velocity Dependent Devices (VDD). With respect to DDD, there are following types of mechanical tests: i) tests of materials, $i$ i) factory production control tests of materials, iii) type tests of devices and $i v$ ) factory production control tests of devices. With respect to the VDD, the European guidelines include the following tests: $i$ ) pressure, $i i$ ) low velocity, iii) constitutive law, $i v$ ) damping efficiency, $v$ ) wind load cycle, $v i$ ) seal wear, and vii) stroke-verification test. In addition, the document establishes that one unit per production lot shall be subjected to three different tests related to factory production control (a production lot is defined as no more than 20 units having the same constitutive law and design details with the exception of the stroke).

\subsection{Cycles of Testing}

The three guidelines establish a different number of cycles of testing for the devices, as follows:

a. ASCE 7-16 (Section 18.6.1.2) indicates that: "each damping device shall be loaded with the following sequence of fully reversed sinusoidal cycles at a frequency equal to $1 /\left(1.5 \mathrm{~T}_{1}\right)$, where $\mathrm{T}_{1}$ is the fundamental period of the structure:

- Ten fully reversed cycles at the displacement in the energy-dissipation device corresponding to 0.33 times the $\mathrm{MCE}_{\mathrm{R}}$ device displacement;

- Five fully reversed cycles at the displacement in the energy-dissipation device corresponding to 0.67 times the $\mathrm{MCE}_{\mathrm{R}}$ device displacement;

- Three fully reversed cycles at the displacement in the energy-dissipation device corresponding to 1.0 times the $\mathrm{MCE}_{\mathrm{R}}$ device displacement; and

- Where the latter test just mentioned produces a force in the energy-dissipation device that is less than the $\mathrm{MCE}_{\mathrm{R}}$ force in the device obtained from analysis, the test shall be repeated at a frequency that produces a force equal to or greater than the $\mathrm{MCE}_{\mathrm{R}}$ force obtained from analysis."

ASCE 7-16 also indicates that "each damping device shall be subjected to the number of cycles expected in the design-wind storm, but not less than 2,000 continuous fully reversed cycles of wind load. Wind load shall be at amplitudes expected in the design windstorm, and shall be applied at a frequency equal to the inverse of the fundamental period of the structure." The document also indicates that it is not necessary to perform the tests if the devices will not be subjected to wind-induced forces or displacements, or if the design wind force is less than the device yield or slip force.

For VDD, the test shall be conducted at a minimum of three temperatures (minimum, ambient and maximum).

b. ES 15129 Guidelines (Section 6.4.4) specify that DDD devices shall be subjected to increasing amplitude cycles at $25 \%, 50 \%$, and $100 \%$ of the maximum displacement, which shall be at least equal to the design displacement $\left( \pm d_{b d}\right)$. The following points shall be applied:

- Five cycles for each intermediate amplitude, and

- At least ten cycles for the maximum amplitude.

Section 7.4.2.7 of ES 15129 specifies that for VDD devices, the loading history at each velocity shall be subjected to $f i v e$ harmonic full cycles of the type: $d(t)=d \sin (2 \Pi f t)$, where the amplitude, $d$, and the frequency, $f$, shall be specified by the Structural Engineer. In addition, ES 15129 document also highlights when wind load is deemed to be critical by the Structural Engineer. The document also specifies that prototype dampers shall be tested in order to verify 
their capacity to resist wind-induced vibrations. The device shall be cycled at a frequency and displacement specified by the Structural Engineer for 200 cycles (e.g. $0.4 \mathrm{~Hz}$ at $+/-12 \mathrm{~mm}$ ).

The document also indicates that the test for VDD devices shall be repeated at the maximum and minimum design temperatures.

c. NTCS-17 (Section B.4.4) specifies that the specimens shall be subjected to a certain number of fully reversed cycles with maximum amplitudes corresponding to the design earthquake associated with the collapse prevention limit state. The numbers of cycles are as follows:

- Fifteen cycles for devices on structural systems with the following characteristics: $i$ ) the structuredamping system is located on soft soil $\left(T_{s} \geq 1 \mathrm{~s}\right)$ where intense narrow-banded seismic motions are commonly registered, and $i$ ) its fundamental vibration period is close to the dominant period of the soil.

- If the structure does not present both characteristics ( $i$ and $i i)$ mentioned in the above paragraph, then the specimens shall be subjected to five fully reversed cycles.

The requirement related to the fifteen cycles is because, in the soft soil zone of Mexico City, there occur long duration intense seismic ground motions. For example, the displacement history of a single-degree-of-freedom system with vibration period $\mathrm{T}=1 \mathrm{~s}$, subjected to the record obtained in the Ministry of Communications and Transportation (SCT) station during the severe earthquake of September 19/1985, with magnitude $\mathrm{M}=8.1$, contains approximately 15 cycles in its intense portion (corresponding to $85 \%$ of Arias intensity). It is noticed that NTCS-17 requires that the excitation period used for the test shall be similar to that of the response vibration period of the structure-damping system.

Section B.4.4 of NTCS-17 also specifies that the specimens shall be subjected to a number of reversed cycles with amplitudes similar to those corresponding to the structural response produced by the design wind at the site of interest, but not less than 2,000 continuous fully reversed cycles corresponding to the wind load with the expected amplitudes of the design windstorm.

For VDD, the tests shall be conducted at three temperatures: minimum, ambient and maximum.

From the above specifications, it can be seen that the number, frequency and amplitude of the test cycles specified in each of the guidelines, are obviously related to the wind and seismic hazards, and with the characteristics of the actions expected at the site.

\subsection{Acceptance Criteria}

ASCE 7-16 and NTCS-17 present similar acceptance criteria for tests of energy dissipation devices. Both documents consider an adequate performance of DDD if the three conditions that follow are satisfied:

- There are no signs of damages including leakage, yielding or breakage.

- The maximum force and the minimum force at zero displacements, as well as at maximum device displacement, for anyone cycle do not differ by more than $15 \%$ from the average maximum and minimum forces as calculated from all cycles, at equal conditions.

- The area of hysteresis loop for anyone cycle does not differ by more than $15 \%$ from the average area of the hysteresis loop as calculated from all cycles in the test.

In addition, ASCE-7-16 specifies the following acceptance criteria:

- The average maximum force and the minimum force at zero displacement, as well as at maximum device displacement, and the average area of the hysteresis loop, calculated for each test shall not differ by more than $15 \%$ from the target values specified by the one responsible for the design of the structure (RDP).

- The average maximum force and the minimum force at zero displacement, as well as at maximum device displacement, and the average area of the hysteresis loop shall fall within the limits specified by the RDP, as described by the nominal properties and the lambda $(\lambda)$ factor for specification tolerance (from section 18.2.4.5 of ASCE 7-16).

- The test lambda factors for damping units shall not exceed the values specified by the RDP.

In addition, NTCS-17 specifies the following: 
- For DDD the effective stiffness, in any cycle, does not differ by more than $15 \%$ from the average effective stiffness as calculated from all cycles in that test. The effective stiffness is defined as:

$$
K_{e f f}=\frac{\left|F_{E D E}^{+}\right|+\left|F_{E D E}^{-}\right|}{\left|D_{E D E}^{+}\right|+\left|D_{E D E}^{-}\right|}
$$

where $F_{E D E}^{+}$and $F_{E D E}$ are the positive and negative forces that correspond to the maximum positive and negative displacement values, $D_{E D E}^{+}$and $D_{E D E}^{-}$, respectively; and the symbol || indicates the absolute value.

The same documents (ASCE 7-16 and NTCS-17) specify the following acceptance conditions for VDD devices:

- There are no signs of damage including leakage, yielding or breakage.

- The maximum force and the minimum force at zero displacement as well as at maximum device displacement, for any cycle, do not differ by more than $15 \%$ from the average maximum and minimum forces as calculated from all cycles in the test, at a specific frequency and temperature.

- The area of hysteresis loop, for any one cycle, does not differ by more than $15 \%$ from the average area of the hysteresis loop as calculated from all cycles in the test, at specific frequency and temperature.

In addition, ASCE 7-16 specifies:

- For VDD with stiffness (for example, viscoelastic devices), the effective stiffness, in any cycle, does not differ by more than $15 \%$ from the average effective stiffness as calculated from all cycles in that test, at a specific frequency and temperature.

- The average maximum and the minimum forces at zero displacement, effective stiffness, and average area of hysteresis loop shall fall within the limits specified by the RDP, as described by the nominal properties and the lambda factor for specification tolerance.

- Test lambda factors $(\lambda)$ for damping units shall not exceed the values specified by the registered design professional.

It is noticed that NTCS-17 does not mention any coefficient (equivalent to $\lambda$ factor) that considers the variation from the nominal properties of the devices.

EN 15129 guidelines specify that in order to assure a stable behavior of the devices under cyclic loading, variations in a series of loads, relevant to the same displacement, shall be limited as follows:

$$
\begin{gathered}
\frac{\left|K_{\text {eff }, i}-K_{\text {eff }, 3}\right|}{K_{\text {eff }, 3}} \leq 0.10 \\
\frac{\left|K_{2, i}-K_{2,3}\right|}{K_{2,3}} \leq 0.10 \\
\frac{\left|\zeta_{\text {eff }, i}-\zeta_{\text {eff }, 3}\right|}{\zeta_{\text {eff }, 3}} \leq 0.10
\end{gathered}
$$

where subscripts 2 and 3 are relevant to quantities at the $2^{\text {nd }}$ and $3^{\text {rd }}$ load cycle, respectively, and subscript $i$ at the $i^{\text {th }}$ load cycle on the test, excluding the first $\left(1^{\text {st }}\right)$ cycle. EN 15129 (Sections 6.2 and 7.3) also provides tolerance limits for different parameters, such as $K_{2}, K_{\text {eff }}, \zeta_{\text {eff }}$ and for the energy dissipation per cycle, corresponding to displacement- and to velocity-dependent devices.

\section{FINAL COMMENTS AND RECOMMENDATIONS}

An overview of the guidelines for the design of structures with passive energy dissipating devices ASCE 7-16, EN 15129 and NTCS-17, is presented; the documents correspond to different seismic regions of the world: USA, Europe and Mexico, respectively; so, obviously they present different requirements related to different laws, formats, 
background, seismic hazard, design philosophies, etc.

Based on the overview, the following comments and recommendations are given in order to contribute to develop in the future better guidelines for designing structures with energy dissipation devices:

General Design Requirements

- NTCS-17 does not mention any factor related to the variation in nominal properties of the devices. It is recommended to consider such variations in the next version of the document, in order to take into account the possible variation in damper properties caused, for example, by aging and environmental effects.

- It is recommended to include some restrictions in future versions of NTCS and of EN about the minimum base shear value $\left(\mathrm{V}_{\min }\right)$ for designing the structural-damping system.

- It is recommended to include some requirements in future versions of NTCS and of EN about the minimum number of energy dissipation devices which shall be located in each story of a building system.

\section{Procedure Selection}

- It is recommended that NTCS-17 and EN 15129 extend, in their future versions, their procedure selection sections. It is noticed that ASCE 7-16 specifies with detail the requirements and methodology for using each approach (modal dynamic, time history analysis, and static procedures).

Inspection of the Structure-Damping Systems

- It is noticed that NTCS-17 recommends specific intervals for inspection of the structures with dampers, while the other two guidelines do not.

\section{Testing of Energy Dissipation Devices}

- The analyzed documents are similar in general testing requirements; however, they present differences that are related to the characteristics of the seismic ground motions that occur in each region.

- ASCE 7-16 and NTCS-17 are similar about acceptance criteria for the devices tests; except that ASCE 7-16 considers, in addition, requirements that account for the variation from nominal properties of the damping devices.

Detailing of the Documents Sections:

- ASCE 7-16 (in Chapter 18) presents with more detail the procedure selection section (methods of analysis of structures with passive energy dissipating devices) than EN 15129 and NTCS-17.

- NTCDS-17 presents with more detail the inspection of the structures section than the other guidelines analyzed.

- EN 15129 (Chapters 6 and 7) presents with more detail the testing section (requirements for testing the antiseismic devices) than the other two guidelines.

\section{CONSENT FOR PUBLICATION}

Not applicable

\section{CONFLICT OF INTEREST}

The author declares no conflict of interest, financial or otherwise.

\section{ACKNOWLEDGEMENTS}

The author appreciates the support given by the Instituto de Seguridad de las Construcciones - Ciudad de México (ISC-CDMX) and the Universidad Nacional Autónoma de México (PAPIIT IN103517). The enthusiastic collaboration of M. A. Santos Santiago and F. Valenzuela Beltran is greatly appreciated.

\section{REFERENCES}

[1] A. Whittaker, I. Aiken, P. Bergman, J. Cohen, J. Kelly, and R. Scholl, "Code requirements for the design and implementation of passive energy dissipation systems", in Energy Dissipation Working Group of the Base Isolation Subcommittee of the Structural Engineers Association of Northern California, CA, USA, 1993.

[2] FEMA 273,NEHRP guidelines for the seismic rehabilitation of buildings", in FEMA Publication 273, Applied Technology Council, USA, 1997. 
[3] FEMA 450, "NEHRP recommended provisions for seismic regulations for new buildings and other structures" in FEMA Publication 450, Building Seismic Safety Council, USA, 2003.

[4] EN 15129 European Standard, Anti-seismic devices, CEN, European Committee for Standardization, 2009.

[5] ASCE/SEI 7-10 Minimum design loads for buildings and other structures, American Society of Civil Engineers, Reston, Virginia, USA, 2010.

[6] S.E. Ruiz, "Recommendations for the design of buildings with energy dissipaters (within the framework of the NTCS of the RCDF), with comments" in Serie I\&D, Instituto de Ingeniería, Universidad Nacional Autónoma de México, SID No. 667, México, 2011.

[7] M. Sarrazín, Requirements for the design of structures with passive energy dissipation systems ", in Preliminary Standard of the Chilean Association of Seismology and Antismism Engineering, Santiago, Chile, 2014.

[8] FEMA P-1050-1 "NEHRP recommended seismic provisions for new buildings and other structures", in FEMA Publication P-1050-1/2015, Building Seismic Safety Council, USA, 2015.

[9] ASCE/SEI 7-16 Minimum design loads for buildings and other structures, American Society of Civil Engineers, Reston, Virginia, USA, 2016.

[10] G.W. Housner, L.A. Bergman, T.K. Caughey, A.G. Chassiakos, R.O. Claus, S.F. Masri, R.E. Skelton, T.T. Soong, B.F. Spencer, and J.T. Yao, "Structural control: Past, present and future", J. Eng. Mech., vol. 123, pp. 897-971, 1997. [http://dx.doi.org/10.1061/(ASCE)0733-9399(1997)123:9(897)]

[11] R.D. Hanson, and T.T. Soong, Seismic design with supplemental energy dissipation devices, Earthquake Engineering Research Institute, EERI Publication No. MNO-8., Oakland, CA., USA. 2001.

[12] S.E. Ruiz, and L. Esteva, "Research and practice in the seismic design of buildings with passive energy dissipating devices in Mexico", In: 7th International Seminar on seismic isolation, passive energy dissipation and active control of vibrations of structures, Assisi, Italy, 2001.

[13] J.E. Martinez Rueda, "On the evolution of energy dissipation devices for seismic design", Earthq. Spectra, vol. 18, pp. 309-345, 2002. [http://dx.doi.org/10.1193/1.1494434]

[14] A. Tena-Colunga, "State of the art of the practice for energy dissipation and seismic isolation of structures in Mexico", In: 10th World Conference on seismic isolation, energy dissipation and active vibration control of structures, Istambul, Turkey, 2007.

[15] M.D.F. Symans, F.A. Charney, A.S. Whittaker, M.C. Constantinou, C.A. Kircher, M.W. Jonhnson, and R.J. McNamara, "Energy dissipation systems for seismic applications: Current practice and recent developments", J. Struct. Eng., vol. 134, pp. 3-21, 2008. [http://dx.doi.org/10.1061/(ASCE)0733-9445(2008)134:1(3)]

[16] T.E. Saaed, G. Nikolakopoulos, J-E. Jonasson, and H. Hedlund, "A state-of-the-art review of structural control systems", J. Vib. Control, vol. 25, pp. 919-937, 2015. [http://dx.doi.org/10.1177/1077546313478294]

[17] P. Clemente, and M. Martelli, "Anti-seismic systems: Worldwide applications and conditions for their correct use", In: $16^{\text {th }}$ World Conference on Earthquake Engineering, Santiago, Chile, 2017.

[18] NTCS-17, “Complementary technical standards for earthquake design” in Regulation of Constructions of the Federal District, Official Gazette of the City of Mexico, Mexico, 2017.

[19] P. Foraboschi, "Versatility of steel in correcting construction deficiencies and in seismic retrofitting of RC buildings", J. Build Eng., vol. 8, pp. 107-122, 2016. [http://dx.doi.org/10.1016/j.jobe.2016.10.003]

[20] M. Priestley, J. N. Calvi, and M. J. Kowalkski, Displacement-Based Seismic Design of Structures, IUSS PRESS: Pavia, Italy, 2007.

[21] A. Teran-Gilmore, and N. Virto, "Preliminary design of low-rise buildings stiffened with buckling-restrained braces by a displacement-based approach", Earthq. Spectra., vol. 25, pp. 185-211, 2009. [http://dx.doi.org/10.1193/1.3054638]

[22] V. Segovia, and S.E. Ruiz, "Direct displacement-based design for buildings with hysteretic dampers, using best combinations of stiffness and strength ratios", J. Earthquake Eng., vol. 21, pp. 752-775, 2017. [http://dx.doi.org/10.1080/13632469.2016.1185054]. [http://dx.doi.org/10.1080/13632469.2016.1185054]

[23] H. Guerrero, A. Terán Gilmore, T. Ji, and J.A. Escobar, "Evaluation of economic benefits of using BRB in hospitals structures located in very soft soils", Eng. Struct., vol. 136, pp. 406-419, 2017.

[http://dx.doi.org/10.1016/j.engstruct.2017.01.038]

[24] Eurocode 8. Part 1. Design of structures for earthquake resistance. European Committee for Standarization, 2004.

[25] Eurocode 8. Part 1. Design of structures for earthquake resistance. European Committee for Standarization, 2011

[26] T. Castillo, and S.E. Ruiz, "Reduction factors for seismic design spectra for structures with viscous energy dampers", J. Earthquake Eng., vol. 18, pp. 323-349, 2014. [http://dx.doi.org/10.1080/13632469.2013.860932].

[http://dx.doi.org/10.1080/13632469.2013.860932]

This is an open access article distributed under the terms of the Creative Commons Attribution 4.0 International Public License (CC-BY 4.0), a copy of which is available at: (https://creativecommons.org/licenses/by/4.0/legalcode). This license permits unrestricted use, distribution, and reproduction in any medium, provided the original author and source are credited. 